\title{
What Can We Learn About Hydrochemical Dynamics of Streamwater during Flood Events in A Forested Karstic Catchment from the Pyrenees Mountains (Southwestern France)?
}

\author{
F. Ulloa-Cedamanos 1,2,3,*, A. Probst 1,2,3, V. Dos-Santos 1,2,3 and J.-L. Probst 1,2,3,* \\ 1 Laboratory of Functional Ecology and Environment, University of Toulouse, CNRS, Toulouse, France \\ 2 LTSER Zone Atelier Pyrénées-Garonne, CNRS, University of Toulouse, France \\ 3 LTER Bassin versant du Baget, SNO Karst, IR OZCAR, CNRS, University of Toulouse, France \\ * Correspondence: francesco.ulloacedamanos@toulouse-inp.fr (F.U.-C.); jean-luc.probst@ensat.fr (J.-L.;P.)
}

\begin{abstract}
Hydrological variations hold a significant influence over the water chemistry in the karst systems within the critical zone. In this context, the Baget Catchment (BC) was monitored at highresolution over two hydrological years. The high-frequency survey at the outlet of BC displayed multiple hydrochemical patterns in response to hydrological variations, mixing water sources, and biogeochemical processes. Among the major elements, sulfate exhibited the widest relative variation during flooding and showed a significant dilution, whereas calcium and bicarbonate revealed a chemostatic behavior as a result of carbonate dissolution in the karst. Hysteretic analysis evidenced the control of different hydrological reservoirs over the stream transport processes of dissolved elements. The concentration of dissolved organic carbon increased during the hydrograph rising limb and was controlled by surface runoff. The relationships between $\mathrm{Ca}^{2+}$ and $\mathrm{HCO}_{3}{ }^{-}$ concentrations and stream-discharge exhibited hysteresis patterns with counterclockwise loops, unlike all other elements, due to the carbonate weathering by biogenic $\mathrm{CO}_{2}$-rich water. Finally, highfrequency sampling during storm events improved the understanding of the factors controlling the hydrochemical dynamic of the Baget stream water. The relative contributions of the karst and epikarst zones, of rainwater, as well as the role of different biogeochemical processes and the hydrological conditions were highlighted.
\end{abstract}

Keywords: carbonate dissolution; chemical weathering; water chemistry; flood events; high frequency monitoring; hydrochemical survey; chemostatic behavior; hysteresis loop; karstic critical zone

\section{Introduction}

The Critical Zone (CZ) is the heterogeneous support at the Earth's surface, in which occur complex interactions between rocks, soils, water, air and living organisms. In the karst systems, the fractured nature of the carbonate rocks and the thin soil cover enhance the water-rock interaction and promote a rapid transfer of surface waters to the underground system (including the epikarst) [1-2]. Despite the uncertainty, the estimation of the average fluxes of carbonate weathering reaches $1.3 \mathrm{Gt}$ $\mathrm{C} \cdot \mathrm{yr}^{-1}$, while the associated $\mathrm{CO}_{2}$ consumption is above $0.1 \mathrm{Gt} \mathrm{C} \cdot \mathrm{yr}^{-1}$ at the global scale [3-4]. The water is a vector of information in the $\mathrm{CZ}$ that allows to elucidate the lithological origin [5], but also the response of the water chemistry face to hydrological changes. In temperate climates, two seasons are contrasted: the dry season mainly during the summer and the wet season with heavy rainfall especially in winter and spring. During the wet season, the forthwith variations due to storms modify the hydrological conditions, leading to dilution processes of major element concentrations [6]. The relationships between the discharge $(\mathrm{Q})$ and the concentration of dissolved elements $(\mathrm{C})$ can either indicate chemostatic or chemodynamic behaviors at the catchment scale [7]. During one entire storm, the plot of C-Q relationship allows to identify loop trajectories, called hysteresis [8]. Depending on 
their shape and direction of rotation, hysteresis analysis provides information about the contributions of different sources/reservoirs (including each flow component of the runoff) to the fluxes of dissolved and particulate matter [9-12], or even the control of seasonal trends based on the environmental factors [13].

The Baget Catchment (BC) in the French Pyrenees Mountains has been monitored since before the 1970s, owning a complete high-resolution hydrogeochemical database [14] coupled with a highfrequency flood survey since 2019. Based on this database, the objectives of this paper are as follows: (i) to investigate the sensitivity (chemostatic or chemodynamic responses) of water chemistry to sudden hydrological variation, (ii) to quantify each flow component of the runoff under rainstorm conditions, (iii) to understand the hysteresis behaviors of chemical compounds and, (iv) to elucidate the dominant controls on changes in hydrochemistry during rainstorm events.

\section{Materials and Methods}

\subsection{Study area}

The BC $\left(42^{\circ} 57^{\prime} 42^{\prime \prime} \mathrm{N}, 0^{\circ} 58^{\prime} 30^{\prime \prime} \mathrm{E}\right)$ is a small $\left(13.25 \mathrm{Km}^{2}\right)$ forested karstic catchment with an altitude range between 498 (at the outlet) and 1417 m.a.s.l. The BC is located in the lower part of the Pyrenees Mountains, in the Southwest of France (Figure 1). It is drained in its lower part by the Lachein stream.

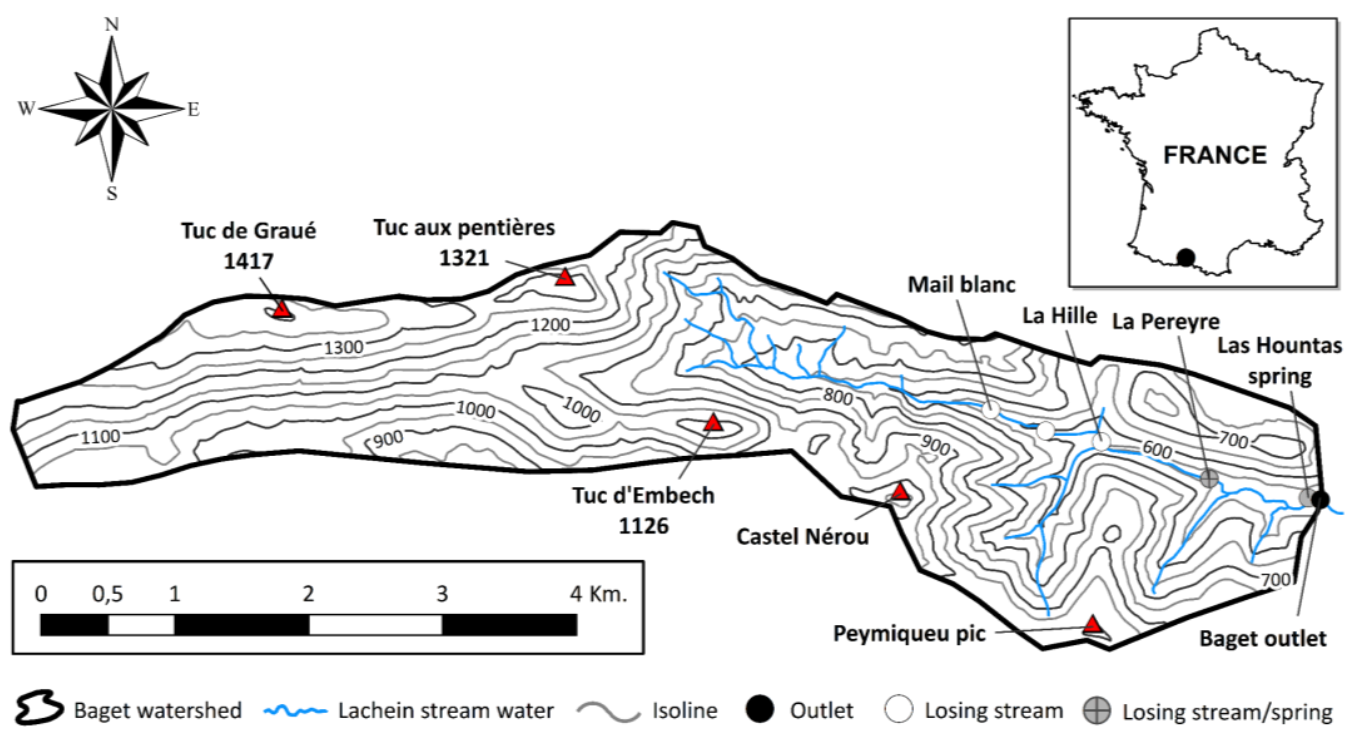

Figure 1. Location and relief of the Baget catchment with contour lines (modified from UlloaCedamanos et al. [14]).

The BC is influenced by an Atlantic oceanic climate coupled with a clear mountainous tendency, leading to a bimodal rainfall regime with runoff peaks of the Lachein stream water in early winter (around December) and late spring (around May) [14]. During the hydrological year 2019-2020 (from October 2019 to September 2020), the $60 \%$ of annual rainfall $\left(1713 \mathrm{~mm} \cdot \mathrm{yr}^{-1}\right)$ occurred from November to December, and from March to May (wet season).

The BC landscape is forested with a predominant forest land cover $(67 \%$ of the basin area in 2019), followed by grasslands located near to the outlet and some pastures in the upper part of BC. This catchment lays on calcareous formations of the Jurassic and Cretaceous represented by a band of limestone bordered to the north and south by impermeable silicate rocks and by dolomitic outcrops in the northern upper section. 


\subsection{Sampling and analysis}

A biweekly sampling was carried out at the BC outlet from October 2018 to May 2020, as well as a high frequency sampling between February 2019 and May 2020 during the flood events.

The physico-chemical parameters such as water temperature (T), specific conductivity (SC), dissolved oxygen (DO) and $\mathrm{pH}$ were measured at the time of sampling using a portable multiparameter (WTW probe, Xylem Analytics Germany Sales GmbH \& Co., Weilheim, Germany). In addition, since April 2014, pressure (water level) and different physico-chemical parameters (T, SC, Turbidity, DO, nitrate and chloride) were measured continuously at a high frequency (10-minute interval) in the mid-depth of the water column (at the outlet) using a multiparameter probe (YSI 6920V2-01, YSI Incorporated, Yellow Springs, OH, USA) equipped with multiple sensors and an atmospheric pressure correction.

Water samples were collected in a clean and dry 1 L HDPE bottle, triple rinsed with stream water before sampling, and stored in darkness at $5{ }^{\circ} \mathrm{C}$ until analyses. All samples were filtered using Millipore $0.22 \mu \mathrm{m}$ cellulose nitrate membranes. Alkalinity was determined using standard acid titration method with $\mathrm{HCl} 0.02 \mathrm{~N}$ and a Metrohm titrant (716 DMS Titrino, Metrohm, Riverview, Florida, USA). Major anion concentrations $\left(\mathrm{SO}_{4}^{2-}, \mathrm{NO}_{3}-\right.$ and $\left.\mathrm{Cl}^{-}\right)$were analyzed by ion chromatography (Dionex apparatus ICS 5000+, Thermo Fisher Scientific, Waltham, MA, USA). Major cation $\left(\mathrm{Ca}^{2+}, \mathrm{Mg}^{2+}, \mathrm{Na}^{+}\right.$and $\left.\mathrm{K}^{+}\right)$and silica concentrations were measured using an acidified sample with $16 \mathrm{~N} \mathrm{HNO}_{3}$, later analyzed by an inductively coupled plasma optical emission spectrometer (ICP-OES; Iris Intrepid II XLD, Thermo Electron, Thermo Fisher Scientific, Waltham, MA, USA). Dissolved Organic Carbon (DOC) was measured on a Shimadzu TOC 5000 analyzer (Shimadzu Corporation, Kyoto, Japan), coupled to the $\mathrm{CO}_{2}$ detection by an infrared gas analyzer (NDIR).

\section{Results and Discussion}

\subsection{Hydrochemical characteristics}

The water temperature and discharge (Figure 2) at the outlet exhibited a clear seasonality during the two hydrological years, but with a completely different Coefficient of Variation $(C V=\sigma / \bar{X})$ : the highest variation for the discharge $(\mathrm{CV}=1.01)$ and the lowest variation for the water temperature $(\mathrm{CV}=0.02)$. The study period is dry compared to the last 40 years [14]. All parameters reflected the hydrological variation.

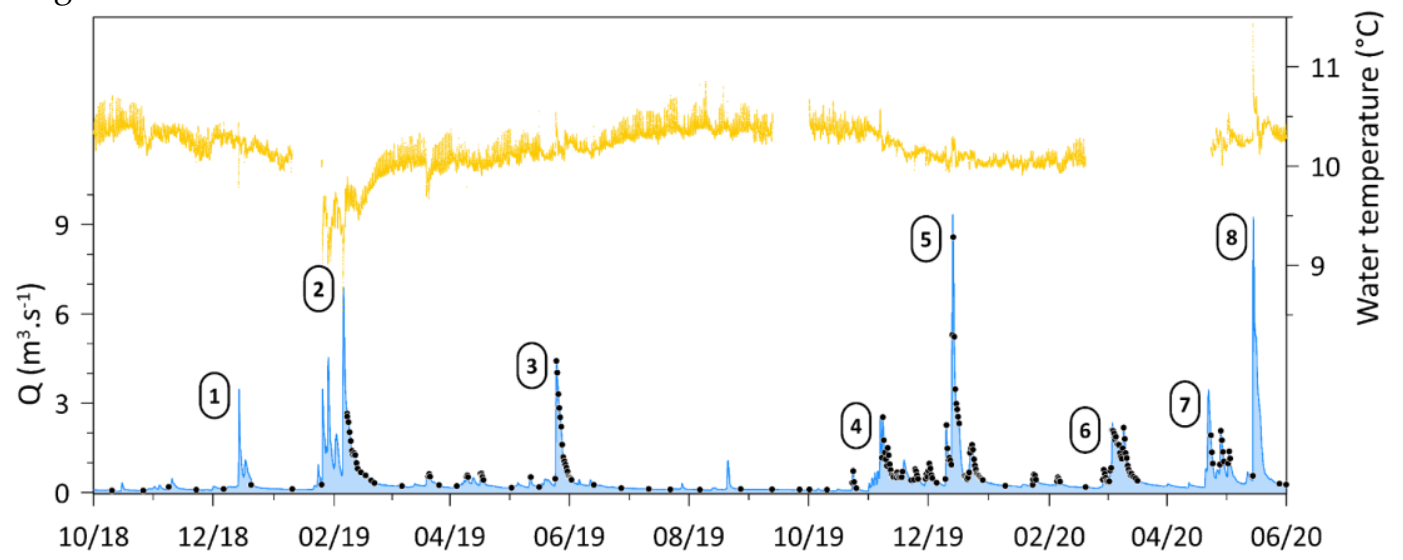

Figure 2. Temporal series of stream discharge (blue line), temperature (yellow line) and sampling periods (black points) for physico-chemical analyses during two hydrological years, from October 2018 to May 2020. The numbers circled refer to the different major floods during the study period.

The stream water in $\mathrm{BC}$ is mildly alkaline and showed low $\mathrm{pH}$ fluctuations $(8.0 \pm 0.2)$. The water temperature is highly stable $\left(10.2 \pm 0.2^{\circ} \mathrm{C}\right)$ throughout the study period. Conductivity showed a slight relationship with total dissolved solids $\left(R^{2}=0.5\right)$, despite their different coefficients of variation $(0.46$ and 0.08 , respectively). 
The mean concentration during the study period exhibited the following pattern: for cations, calcium $\left(\mathrm{Ca}^{2+}, 88.7 \%\right.$ of total cationic concentration in $\left.\mu \mathrm{eq} \cdot \mathrm{L}^{-1}\right) \gg$ magnesium $\left(\mathrm{Mg}^{2+}, 9.8 \%\right)>>$ sodium $\left(\mathrm{Na}^{+}, 1.1 \%\right)>$ potassium $\left(\mathrm{K}^{+}, 0.4 \%\right)$ and for anions, bicarbonate $\left(\mathrm{HCO}_{3}^{-}, 93.1 \%\right.$ of total anionic concentration in $\left.\mu \mathrm{eq} \cdot \mathrm{L}^{-1}\right)>>$ sulphate $\left(\mathrm{SO}_{4}{ }^{2-}, 4.6 \%\right)>$ chloride $(\mathrm{Cl}-1.4 \%)>$ nitrate $\left(\mathrm{NO}_{3}, 0.8 \%\right)$. The predominance of $\mathrm{Ca}^{2+}, \mathrm{Mg}^{2+}$ and $\mathrm{HCO}_{3}$ is related to the carbonate lithology of $\mathrm{BC}$ [14]. The dischargeweighted mean concentration of sulphate has clearly decreased $\left(0.15 \mu \mathrm{eq} \cdot \mathrm{L}^{-1}\right)$ during the study period

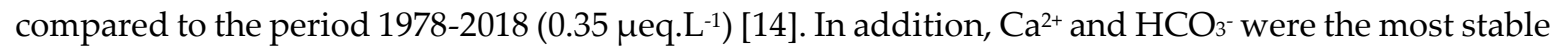
ions, while $\mathrm{SO}_{4}{ }^{2-}, \mathrm{K}^{+}, \mathrm{NO}_{3}{ }^{-}$and DOC exhibited high $\mathrm{CV}$. The Net Inorganic Charge Balances (NICB = $\left.2 \times\left(\mathrm{TZ}^{+}-\mathrm{TZ}^{-}\right) /\left(\mathrm{TZ}^{+}+\mathrm{TZ}\right) \times 100\right)$ between the sum of anions (TZ) and the sum of cations $\left(\mathrm{TZ}^{+}\right)$(both in meq. $\left.\mathrm{L}^{-1}\right)$ never exceeded $\pm 10 \%$ for all the samples.

In this study, only the individual flood event No. 3 (Figure 2, the last flood of the hydrological year 2018-2019) was analyzed further as an example. This individual flood event is representative of $\mathrm{BC}$ regarding intensity/magnitude, besides it is not influenced by past and/or successive floods and the recession period is not disturbed.

\subsection{Separation of the flood flow components}

The onset of a storm period was established when the discharge increased suddenly exhibiting a marked inflection (Point B, Figure 3A). This sudden change was assessed when the discharge change rate (DCR, Equation 1) was greater than $100 \%$.

$$
D C R=\left(Q_{i+1}-Q_{i}\right) / Q_{i}
$$

where $Q_{i}$ and $Q_{i+1}$ are the daily discharge at time-step $i$ and $i+1$. The end of the storm period was determined when the DCR was greater than $-20 \%$ and the base discharge was lower than $300 \mathrm{~L} \cdot \mathrm{s}^{-1}$ in BC (Point E, Figure 3A). Moreover, small floods leading to discharge variation only within $\pm 1 \mathrm{~m}^{3} \cdot \mathrm{s}^{-1}$ were not considered. As result, eight hydrological events were differenced according to this approach (Figure 2).
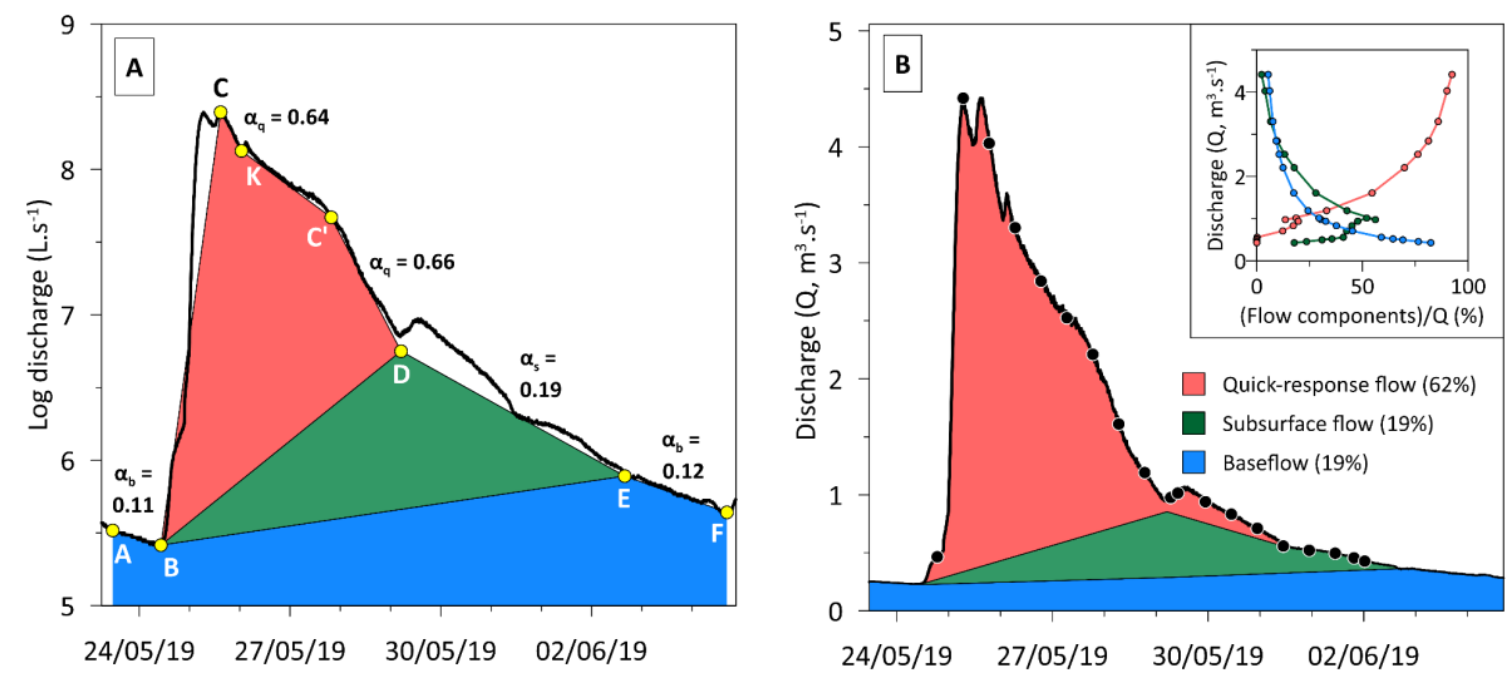

Figure 3. Hydrograph separation (A- in logarithmic scale and B- in normal scale) of the flood event No.3 with the respective recession coefficients $\left(\alpha_{\mathrm{q}}, \alpha_{\mathrm{s}}, \alpha_{\mathrm{b}}\right.$, corresponding to $\mathrm{t}$ in days, see equation 2$)$ for the respective flow components. The embedded small graph exhibits the relationship between the discharge of each flow component and the total discharge during the falling limb. The black points on the hydrograph B correspond to water sampling.

The flows were split according to the hydrograph separation method of Probst [15-17]. This method was adapted for karst systems, assuming that the quick-response flow (karst and surface runoff fraction), the subsurface flow (epikarst and infiltration fraction) and the baseflow (groundwater fraction) occur simultaneously. The quantitative analysis of these curves is derived from the research of Maillet [18] who indicated that the recession curve of the hydrograph during a 
storm period can be characterized by an exponential decrease of the discharge (Equation 2), suggesting a linear relationship between piezometric head and flowrate [19].

$$
Q_{t}=Q_{0} * e^{-\alpha t}
$$

where $Q_{t}$ is the instantaneous discharge at time-step $t$ (in days in our study), $Q_{0}$ is the initial discharge at time zero and $\alpha$ is the recession coefficient. This coefficient depends on the characteristics of each flow associated with the reservoir that drains, allowing to differentiate the different reservoirs on the basis of their $\alpha$ coefficient.

The hydrograph separation of the flood event No.3 (Figure 3A) exhibited three distinct recession coefficients for : the quick-response flow $\left(\alpha_{q}: 0.64-0.66\right)$, the subsurface flow $\left(\alpha_{\mathrm{s}}: 0.19\right)$ and the baseflow $\left(\alpha_{\mathrm{b}}: 0.11-0.12\right)$. The analysis of the other flood events in BC (Figure 2) showed that the different recession coefficients $\alpha$ (with $\mathrm{t}$ in days) range between 0.80 and 0.40 for $\alpha_{\mathrm{q}}$, from 0.20 to 0.10 for $\alpha_{\mathrm{s}}$ and between 0.12 and 0.04 for $\alpha_{\mathrm{b}}$.

The analysis of the flow distribution along the flood recession (Figure 3B) showed that the dominance of the quick-response flow decreases progressively, being the dominant streamflow component ( $>50 \%$ of total discharge) up to discharges higher than $1.5 \mathrm{~m}^{3} \cdot \mathrm{s}^{-1}$, while the subsurface flow is the dominant flow for discharges close to $1 \mathrm{~m}^{3} \cdot \mathrm{s}^{-1}$. Likewise, the baseflow correspond to discharges lower than $0.65 \mathrm{~m}^{3} . \mathrm{s}^{-1}$.

\subsection{Temporal variations and $C-Q$ relationships}

The control of discharge over the dissolved elements can be represented by the comparison of temporal variations for discharges and solute element concentrations during the flood event (Figure 4). Unlike the other elements, $\mathrm{Ca}^{2+}$ and $\mathrm{HCO}_{3}{ }^{-}$are the only dissolved elements that increase during the quick-response flow of the falling limb (Figure 3B and 4A). As a consequence of the change in flow component (subsurface flow), a clear decrease is observed for $\mathrm{Ca}^{2+}$ and $\mathrm{HCO}_{3}$, followed by a progressive increase in the concentrations with the dominance of the baseflow.

These temporal variations of both discharge and concentrations can be analyzed also using the relationships between concentrations and discharges which generally follow a power-law function (Equation 3; [20]):

$$
C_{i}=a Q_{i}^{b}
$$

where $Q_{i}$ and $C_{i}$ are the instantaneous discharges and dissolved element concentrations respectively, at time-step $i$. The exponent $b$ is a useful indicator of the chemodynamic features of dissolved element behavior. If $b<0$, the dilution effect produced by $Q$ is the only regulator on $C$; if $b$ $=0, C$ exhibits a chemostatic behavior, without influence of $Q$ variation; if $b>0$, an enrichment takes place on the solutes when the discharge increases.

The normalized C-Q patterns (see above section 3.4 and Figure 5), suggest that the dilution effect due to the increased discharge is affected by other processes supplying additional inflows of solute elements with the change in discharge [21]. $\mathrm{SO}_{4}{ }^{2-}(\mathrm{b}=-0.26)$ exhibited the most negative $\mathrm{b}$ value, indicating a strong dilution effect on the concentration as the discharge increases. These smaller bvalues revealed slower outputs or reduced amounts of this anion in the BC, which potentially comes from the gypsum dissolution, and to a lesser extent from pyrite oxidation and atmospheric contribution [14]. DOC was the only parameter with a clear enrichment with the discharge increase $(b=0.16) . \mathrm{Ca}^{2+}(b=-0.05)$ and $\mathrm{HCO}_{3}{ }^{-}(b=0.05)$ displayed $b$ values close to 0 , reflecting an overall chemostatic behavior. Such strong chemostatic behavior could initially be based on a counterbalance between their low-concentration in rainwater input and the rapid kinetic of carbonate dissolution with biogenic soil $\mathrm{CO}_{2}[12]$, indicating a control by process-limited regime.

\subsection{Hysteresis analysis}

The C-Q relationships are widely used to define the origin and transfer of elements $[11,22,23]$. During a flood, the $\mathrm{C}-\mathrm{Q}$ relationship can take the shape of a straight line or a loop, called hysteresis 
[23]. These hystereses reflect different concentration responses to the same discharge during the rising and falling limbs of the hydrograph.
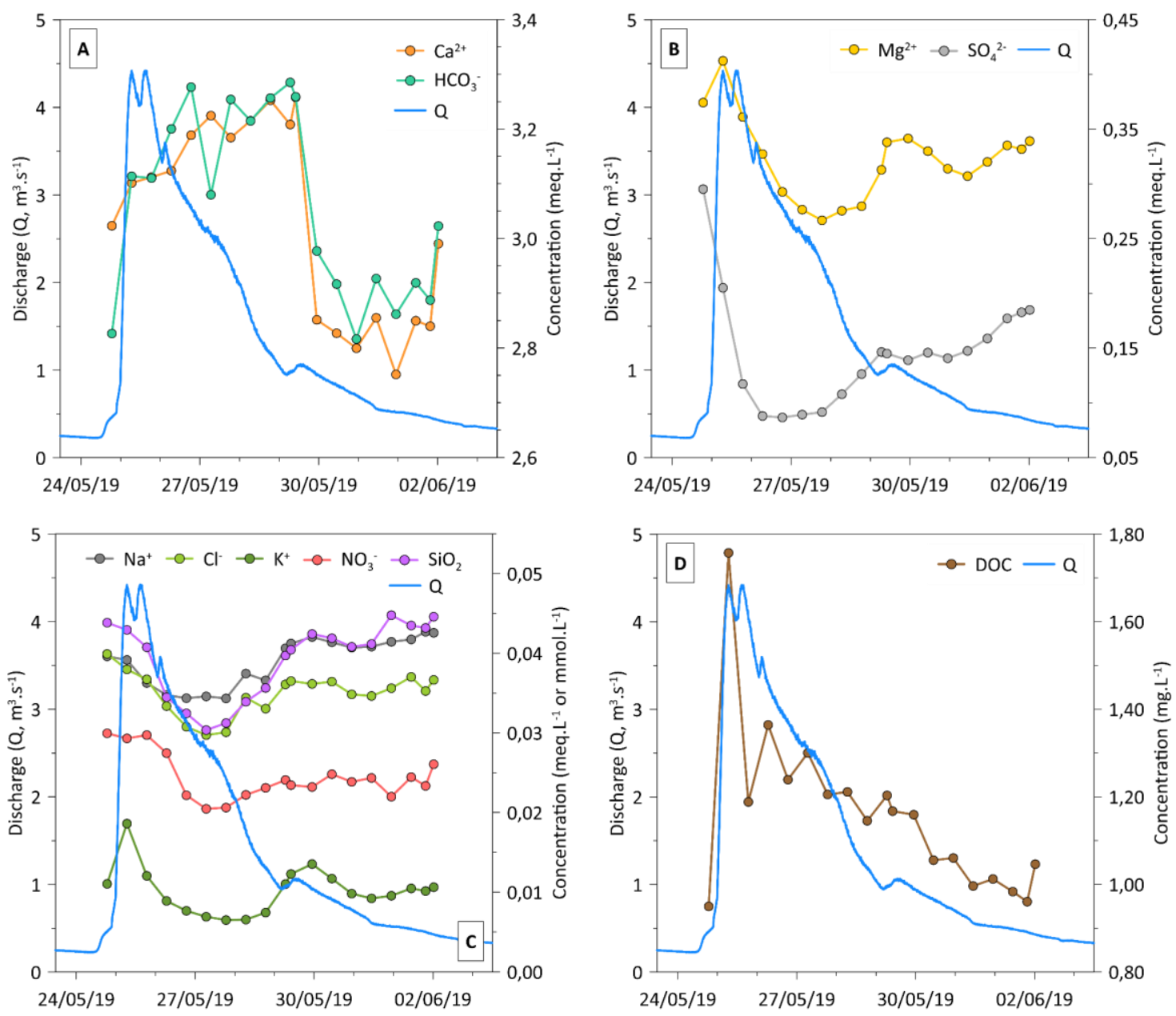

Figure 4. Temporal series of discharge $\left(\mathrm{Q}, \mathrm{m}^{3} \cdot \mathrm{s}^{-1}\right)$ and major element concentrations $\left(\mathrm{A}-\mathrm{Ca}^{2+}\right.$ and $\mathrm{HCO}_{3}{ }^{-}$in meq. $\mathrm{L}^{-1}, \mathrm{~B}-\mathrm{Mg}^{2+}$ and $\mathrm{SO}_{4}{ }^{2-}$ in meq. $\mathrm{L}^{-1}, \mathrm{C}-\mathrm{Na}^{+}, \mathrm{K}^{+}, \mathrm{NO}_{3}{ }^{-}$and $\mathrm{Cl}^{-}$in meq. $\mathrm{L}^{-1}$ and $\mathrm{SiO}_{2}$ in $\mathrm{mmol}^{-\mathrm{L}^{-}}$ $\left.{ }^{1}\right)$ as well as for dissolved organic carbon (D- DOC in mg. $\mathrm{L}^{-1}$ ) during the flood event No. 3 .

The Hysteresis Index (HI) [24], based on normalized data, was used to compare the hysteresis behavior of each parameter within and between different flood events (Equation 4, 5 and 6).

$$
\begin{gathered}
\text { Normalized } Q_{i}=\left(Q_{i}-Q_{\min }\right) /\left(Q_{\max }-Q_{\min }\right) \\
\text { Normalized } C_{i}=\left(C_{i}-C_{\min }\right) /\left(C_{\max }-C_{\min }\right) \\
H I=C_{i-R L_{-} n o r m}-C_{i-F L_{-} n o r m}
\end{gathered}
$$

where $Q_{i}$ and $C_{i}$ are the instantaneous discharge and dissolved element concentrations at timestep i, respectively. The $\mathrm{Q}_{\min }, \mathrm{Q}_{\max }$ and $\mathrm{C}_{\min }, \mathrm{C}_{\max }$ correspond to the minimum and maximum values of discharges and concentrations during a complete flood event, respectively. The $\mathrm{C}_{\mathrm{i}-\mathrm{RL} \_ \text {norm }}$ and $\mathrm{C}_{\mathrm{i}}$ FL_norm refer to the normalized concentrations on the rising limb (RL) and on the corresponding falling limb (FL) of the hydrograph respectively, for each $10 \%$ increase in discharge [24].

Loop trajectories of dissolved elements evidenced different hysteresis behaviors (Figures 5A-F). Hysteresis loops of almost all dissolved elements exhibited clockwise trajectories, except for $\mathrm{HCO}_{3}$, $\mathrm{Ca}^{2+}$, whose trajectories were counterclockwise. The loops were relatively higher in magnitude (mean $\mathrm{HI}>0.4$ ), except for $\mathrm{Ca}^{2+}$ (Figure 5A) and DOC (Figure 5F), whose HI tended to zero. DOC also exhibited a form in eight increasing the $\mathrm{HI}$ at high discharge (the embedded figure in Figure $5 \mathrm{~F}$ ), suggesting a source of DOC mobilized during flood events and a regulation by a transport-limited 
regime. In addition, the DOC revealed a clear upward trend in the ascending limb, while $\mathrm{Ca}^{2+}, \mathrm{HCO}_{3}{ }^{-}$ , $\mathrm{Mg}^{2+}$ and $\mathrm{K}^{+}$(Figures 5A and 5C) also showed an increasing trend but with a less pronounced slope. The enrichment in $\mathrm{K}^{+}$could be due to of cation exchange in soils and to its high availability within the biomass [25]. The quick transport of ions suggested an piston effect of more concentrated water, which is afterwards diluted as the discharge increases.
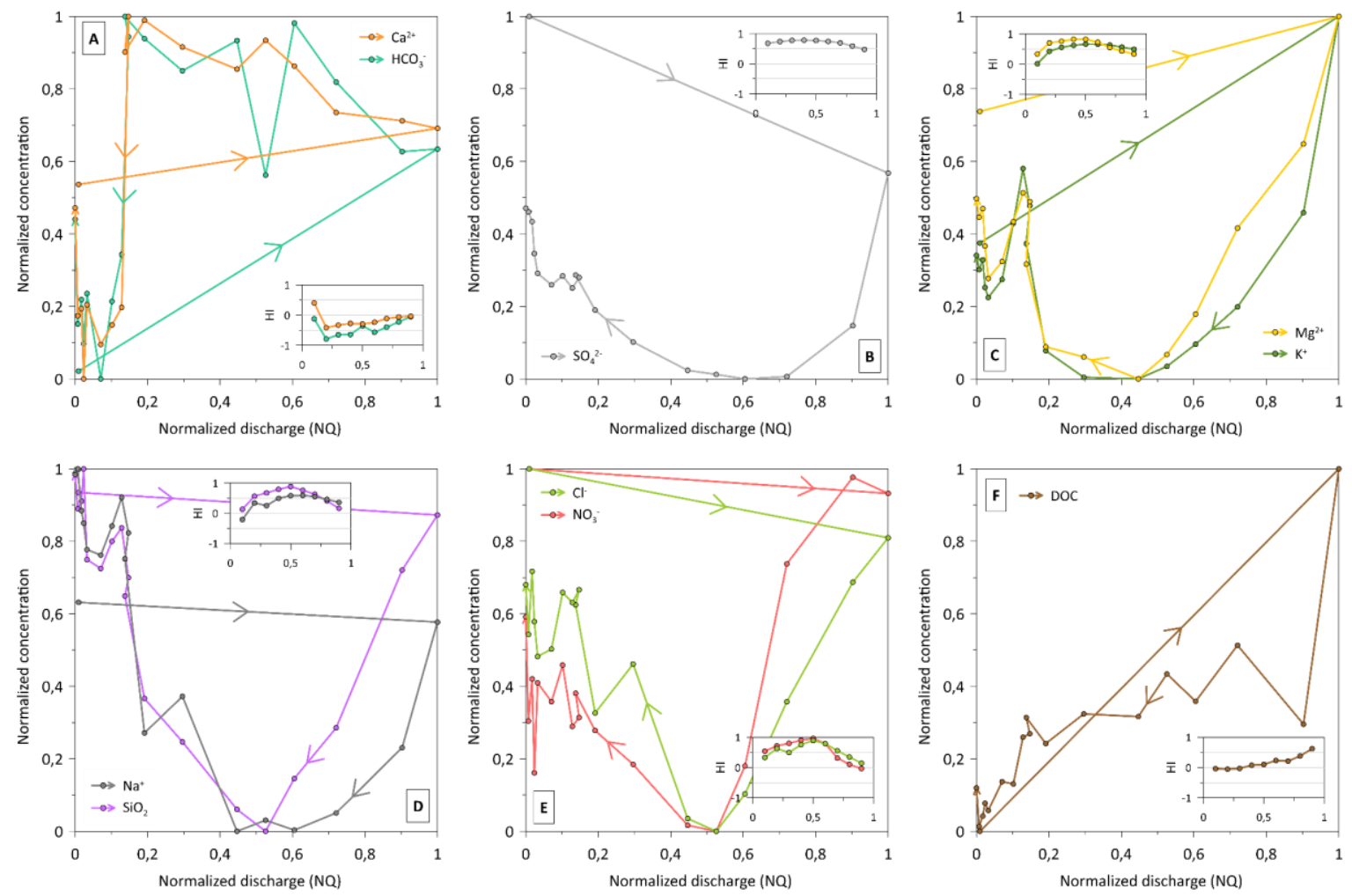

Figure 5. Normalized hysteresis loops for major elements during the flood event No. 3. Small plots show the hysteresis index (HI) vs the normalized discharge for each element during the flood episode.

During the rising limb of the flood event, the $\mathrm{NO}_{3}$ - exhibits a chemostatic behavior because the leaching of the fir and beech forest, a quick access source of $\mathrm{NO}_{3}{ }^{-}$, would compensate the sudden increase in discharge [14]. Conversely, the rest of dissolved elements, mainly SO $4^{2-}$, displayed a downward trend in the ascending limb. $\mathrm{Na}^{+}$exceeded $\mathrm{Cl}^{-}$(Figure $4 \mathrm{C}$ ), their small gap can be related to an additional source besides the atmosphere, such as the weathering of silicate rocks located at the lower southern section. It is reinforced by the similarity of the hysteresis pattern between $\mathrm{SiO}_{2}$ and $\mathrm{Na}^{+}$( Figure 5D). Regarding the falling limb, $\mathrm{Ca}^{+}$and $\mathrm{HCO}_{3}{ }^{-}$were the only ions with an upward trend until the end of the quick-response flow composed by the karst flow (Figure $3 \mathrm{~B}$ and $4 \mathrm{~A}$ ). The rapid mobilization of dissolved elements and the hydrological conditions (last flood of the hydrological year 2018-2019) deplete the reserves (such as the epikarst included in the subsurface flow) and hinder an immediate return to the initial conditions, in particular for source-limited elements such as $\mathrm{SO}_{4}^{2-}$ (Figure 5B) [12].

\section{Conclusions}

This paper revealed chemodynamic and hysteresis behaviors of water chemistry in response to discharge variations in a karst forest catchment located in the French Pyrenees Mountain. $\mathrm{Ca}^{2+}$ and $\mathrm{HCO}_{3}$ - exhibited an overall chemostatic behavior due to the rapid kinetic of carbonate dissolution with biogenic soil $\mathrm{CO}_{2}$, suggesting a control by process-limited regime. Additionally, $\mathrm{Ca}^{2+}$ and $\mathrm{HCO}_{3}{ }^{-}$ are the only dissolved elements that increase during the quick-response flow mainly constituted by the karst flow contribution. The fast mobilization and the antecedent hydrological conditions deplete the epikarst (included in the subsurface flow) reserves of dissolved elements and delay a quick return to the initial conditions. The chemodynamic response of $\mathrm{SO}_{4}{ }^{2-}$ displayed a strong rainwater dilution 
as the discharge increases, linked to a slower outputs and/or reduced amount sources. The hysteresis analysis revealed clockwise trajectories for most of ions, except for $\mathrm{HCO}_{3}{ }^{-}$and $\mathrm{Ca}^{2+}$, suggesting an initial piston effect of more concentrated water in the basin, which is then diluted with the increase in discharge. Conversely, DOC exhibited a form in eight with a general increase with increasing discharge, suggesting (i) a source of DOC mobilized during flood events, most likely from the surface of soils (plant litter), and (ii) a regulation by a transport-limited regime. This research revealed the importance of the high resolution hydrochemical survey in the karst systems, whose biogeochemical dynamic plays a key role in the global carbon cycle in this karstic catchment. Further in-depth research will be necessary to understand the dynamics of the water-carbon mechanisms in the critical zone to develop robust predictive models.

Acknowledgments: The authors are particularly grateful for the support from SNO KARST, OZCAR, CNRS INEE, INSU and Zone Atelier Pyrénées-Garonne (LTSER ZA PYGAR). The data of this research were collected and partly monitored under the initiative of the French KARST Observatory Network SNO KARST (www.sokarst.org) initiative of the INSU/CNRS, whose purpose is to reinforce the exchange of knowledge and encourage interdisciplinary research on karst systems. The SNO Karst is also a member of the French Research Infrastructure OZCAR, the French network of Critical Zone Observatories. The analytical platforms of the Laboratory of Functional Ecology and Environment, PAPC (F. Julien, D. Lambrigot, and W. Amblas) and the chemical laboratory department of the GET (C. Causserand and P. Besson) make a significant contribution to the analytical work. F. Ulloa-Cedamanos's PhD was financed by a fellowship from the French Ministry of Higher Education, Research and Innovation. Our special thanks go to those who assisted in the fieldwork or in the analytical work during a given period.

Author Contributions: Conceptualization, F.U.-C., A.P., and J.-L.P.; methodology, F.U.-C., A.P., and J.-L.P.; validation, F.U.-C., A.P., and J.-L.P.; formal analysis, F.U.-C.; investigation, F.U.-C., A.P., and J.-L.P.; resources, F.U.-C., and V.D-S.; data curation, F.U.-C.; writing-original draft preparation, F.U.-C.; writing-review and editing, A.P. and J.-L.P.; visualization, F.U.-C.; supervision, A.P. and J.-L.P.; project administration, A.P. and J.L.P.; funding acquisition, A.P. and J.-L.P.

Conflicts of Interest: The authors declare no conflict of interest.

\section{Abbreviations}

The following abbreviations are used in this manuscript:

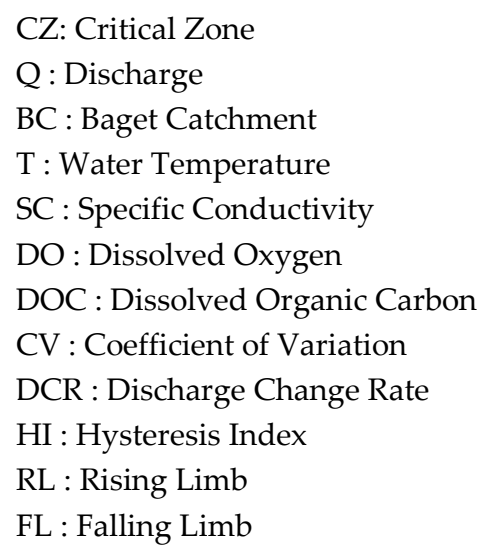

\section{References}

1. Bakalowicz, M. Epikarst. In Encyclopedia of Caves, 2nd ed.; Academic Press: Cambridge, MA, USA, 2012; pp. 284-288.

2. Beaulieu, E.; Goddéris, Y.; Donnadieu, Y.; Labat, D.; Roelandt, C. High sensitivity of the continentalweathering carbon dioxide sink to future climate change. Nat. Clim. Chang. 2012, 2 (5), 346-349.

3. Gaillardet, J.; Dupre, B.; Louvat, P.; Allegre, C.J. Global silicate weathering and $\mathrm{CO}_{2}$ consumption rates deduced from the chemistry of large rivers. Chem. Geol. 1999, 159, 3-30.

4. Amiotte-Suchet, P.; Probst, J.-L.; Ludwig, W. Worldwide distribution of continental rock lithology: Implications for the atmospheric/soil CO2 uptake by continental weathering and alkalinity river transport to the oceans. Glob. Biogeochem. Cycles 2003, 17. 
5. Bakalowicz, M. Contribution de la Géochimie des Eaux a la Connaissance de L'aquifère Karstique et de la Karstification. Ph.D. Thesis, Université Pierre et Marie Curie, Paris, France, 1979.

6. Huang, X.; Fang, N.F.; Zhu, T.X.; Wang, L.; Shi, Z.H.; Hua, L. Hydrological response of a large-scale mountainous watershed to rainstorm spatial patterns and reforestation in subtropical China. Sci. Total Environ. 2018, 645, 1083-1093.

7. Musolff, A.; Schmidt, C.; Selle, B.; Fleckenstein, J.H. Catchment controls on solute export. Adv. Water Resour. 2015, 86, 133-146.

8. Williams, G.P. Sediment concentration versus water discharge during single hydro- logic events in rivers. J. Hydrol. 1989, 111 (1), 89-106.

9. Evans, C.; Davies, T.D. Causes of concentration/discharge hysteresis and its potential as a tool for analysis of episode hydrochemistry. Water Resources Research. 1998, 34(1), 129-137.

10. Darwiche-Criado, N.; Comín, F.A.; Sorando, R.; Sánchez-Pérez, J.M. Seasonal variability of $\mathrm{NO}_{3}^{-}$ mobilization during flood events in a Mediterranean catchment: the influence of intensive agricultural irrigation. Agric. Ecosyst. Environ. 2015, 200, 208-218.

11. Baker, E.B.; Showers, W.J. Hysteresis analysis of nitrate dynamics in the Neuse River, NC. Sci. Total Environ. 2019, 652, 889-899.

12. Qin, C.; Li, S.-L.; Waldron, S.; Yue, F.-J.; Wang, Z.-J.; Zhong, J.; Ding, H.; Liu, C.-Q. High-frequency monitoring reveals how hydrochemistry and dissolved carbon respond to rainstorms at a karstic critical zone, Southwestern China. Sci. Total Environ. 2020, 714, 136833.

13. Johnson, F. A.; and J. W. East. Cyclical relationships between river discharge and chemical concentrations during flood events. J. Hydrol. 1982, 57, 93-106.

14. Ulloa-Cedamanos, F.; Probst, J.-L.; Binet, S.; Camboulive, T.; Payre-Suc, V.; Pautot, C.; Bakalowicz, M.; Beranger, S.; Probst, A. A Forty-Year Karstic Critical Zone Survey (Baget Catchment, Pyrenees-France): Lithologic and Hydroclimatic Controls on Seasonal and Inter-Annual Variations of Stream Water Chemical Composition, $\mathrm{pCO}_{2}$, and Carbonate Equilibrium. Water 2020, 12, 1227.

15. Probst J.-L. Hydrologie du bassin de la Garonne. Modèle de mélanges. Bilan de l'érosion. Exportation des phosphates et des nitrates. Thèse de Doctorat, Toulouse III, 1983.

16. Probst, J.-L. Nitrogen and phosphorous exportation in the Garonne basin (France). Hydrology. 1985, 76, 281-305.

17. Probst J.-L. Dissolved and suspended matter transported by the Girou River (France): mechanical and chemical erosion rates in a calcareous molasse basin. Hydrol. Sci. J. 1986, 31, 1, 61- 79.

18. Maillet, E. Essai d'hydraulique souterraine et fluviale, Libraire Sci., A. Herman, Paris, 1905.

19. Dewandel, B., Lachassagne, P., Bakalowicz, M., Weng, P., Al-Malki, A. Evaluation of aquifer thickness by analysing recession hydrographs. Application to the Oman ophiolite hard-rock aquifer. J. Hydrol. 2003, $274(1-4), 248-269$.

20. Godesy, S.E.; Kirchner, J.W.; Clow, D.W. Concentration-discharge relationships reflect chemostatic characteristics of US catchments. Hydrological Processes, 2009, 23, 13, 1844-1864.

21. Clow, D.W.; Mast, M.A. Mechanisms for chemostatic behavior in catchments: Implications for $\mathrm{CO}_{2}$ consumption by mineral weathering. Chem. Geol. 2010, 269, 40-51.

22. El Azzi, D.; Probst, J.L.; Teisserenc, R.; Merlina, G.; Baque, D.; Julien, F.; Guiresse, M. Trace element and pesticide dynamics during a flood event in the save agriculture watershed: soil-river transfer pathways and controlling factors. Water Air Soil Pollution. 2016, 227 (12), 227-442.

23. Lloyd, C.E.; Freer, J.E.; Johnes, P.J.; Collins, A.L. Using hysteresis analysis of high- resolution water quality monitoring data, including uncertainty, to infer controls on nutrient and sediment transfer in catchments. Sci. Total Environ. 2016, 543 (2016), 388-404.

24. Lloyd, C.E.M.; Freer, J.E.; Johnes, P.J.; Collins, A.L. Technical note: testing an improved index for analysing storm discharge-concentration hysteresis. Hydrol. Earth Syst. Sci. 2016, 20 (2), 625-632.

25. Boy, J.; Valarezo, C.; Wilcke, W. Water flow paths in soil control element exports in an Andean tropical montane forest. Eur. J. Soil Sci. 2008, 59 (6), 1209-1227. 